\title{
Research on Joint Cultivation Mechanism of Adult Education under Collaborative Innovation Environment in China
}

\author{
Yuzhen Duan \\ College of Economic and Management, Anhui Open University, Hefei, China \\ Email: dyzp88@mail.ustc.edu.cn
}

How to cite this paper: Duan, Y. Z. (2020). Research on Joint Cultivation Mechanism of Adult Education under Collaborative Innovation Environment in China. Creative Education, 11, 797-805. https://doi.org/10.4236/ce.2020.115057

Received: April 14, 2020

Accepted: May 22, 2020

Published: May 25, 2020

Copyright (อ 2020 by author(s) and Scientific Research Publishing Inc. This work is licensed under the Creative Commons Attribution International License (CC BY 4.0).

http://creativecommons.org/licenses/by/4.0/

\section{(c) (i) Open Access}

\begin{abstract}
Under the initial formation of collaborative innovation environment in China, adult education is also quietly playing a role in the cooperation among various innovative subjects. Among universities, between universities and scientific research institutions, and between universities and local innovation forces, through the joint training of high-level talents, to achieve adult education cooperation, the mode of repeated innovation, the quality advantage of joint training of talents is increasingly obvious. Based on previous studies, this paper analyzes new characteristics of the adult education in the era of collaborative innovation, and proposes countermeasures against challenges to adult education of collaborative innovation from four aspects.
\end{abstract}

\section{Keywords}

Collaborative Innovation, Adult Education, Joint Cultivation Mechanism, Multi-Subject Participation, Quality-Oriented Education

\section{Introduction}

With the initial formation of collaborative innovation environment in China, adult education is also quietly playing a role in the cooperation among various innovative subjects. Among universities, between universities and scientific research institutions, and between universities and local innovation forces, through the joint training of high-level talents, to achieve adult education cooperation, the mode of repeated innovation, the quality advantage of joint training of talents is increasingly obvious.

Under the background of collaborative innovation, the joint cultivation mechanism of adult education, as a new mode different from the previous single 
cultivation of adult education in colleges and universities, has important practical and exploratory significance in the pioneering exploration of breaking through the traditional institutional barriers and realizing the improvement of adult education cultivation quality. In spite of multi-subject participation in adult education, joint training model in the field of higher education is still a short practice. Researchers and management workers engaged in adult education at home and abroad, from the two aspects of model research and specific process management, and around the hot issues from different perspectives to carry out a unilateral discussion. However, most of studies are caused by practical problems or specific cases, lack of analysis on the new characteristics of adult education in the context of collaborative innovation.

\section{Literature Review}

In spite of this collaborative innovation environment, the multi-subject joint cultivation mode of adult education is still a short practice in the field of higher education. The theoretical researchers and management workers engaged in adult education have published many related papers, mainly from the two aspects of model research and specific process management. Most of these studies are initiated by practical problems or specific cases, and the hot issues are discussed unilaterally from different perspectives.

\section{1) The research on joint cultivation of adult education}

The Sino-foreign joint the main way to cultivate high-level talents, and improve the mechanism of the joint training countermeasures. Some scholars have also pointed out that Sino-foreign joint training is one of the basic connotations of the internationalization of talent training in universities, which involves further expanding the space and scale of Sino-foreign joint training (Bitton et al., 2014). Other scholars in this field have conducted early research on the issue of "broadening the road of joint training of higher education by colleges and universities training more applied talents for the development of electronic science and technology". In addition, some paper discusses the significance, management and methods of joint training of colleges and universities as well as the problems that should be paid attention (Dwyer, 2013). In terms of introducing the student base of joint adult education, students from mainland China are more interested in joint adult education (Bodycott, 2009).

\section{2) The perspective of multi-subject participation}

The most characteristic of this research is the joint cultivation research of the unification of industry, university and research institute, and there are many such theoretical literature and case studies (Glicken et al., 2013). This kind of literature mainly focuses on the research on the mode, path, system and quality assurance mechanism of joint cultivation of adult education by universities, scientific research and production departments. In terms of discussing the joint cultivation of adult education, it is positive to the joint cultivation of adult education by enterprises and universities using the methods of cooperative education and internship (Guan, 2018). In discussing the necessity of joint adult education, it 
pointed that the emergence of globalization and supranational organizations requires joint adult education in higher education management (Dwyer, 2013). The joint cultivation of adult education for graduate students, it was pointed out that no matter in science, engineering, social sciences could be implemented to jointly cultivate adult education for graduate students, which was also an important way to solve the problems existing in the cultivation of adult education for graduate students in East Africa (Ssempebwa et al., 2012). In the discussion of the motivation and feasibility of joint cultivation of adult education, the motivation of internationalization includes business advantages, knowledge and language acquisition, strengthening international standards, etc. Meanwhile, the efforts to monitor and ensure quality are the indispensable educational environment for joint cultivation of adult education.

As mentioned above, the main characteristics of the current theoretical literature and case analysis on the joint cultivation of adult education are as follows. Firstly, from the perspective of the research subject, it is mainly limited to the study of the mode of joint cultivation of adult education between two subjects. Secondly, from the perspective of research content, it mainly focuses on the specific key issues in process management under a certain mode, which the research on some key issues in joint cultivation is still vacant. For the development or formation of the collaborative innovation environment that it breaks through the institutional barriers, various innovative subjects can play in the joint cultivation of adult education, as well as the exploration and establishment of the effective mechanism for multiple subjects to participate in the joint cultivation.

\section{New Characteristics of the Adult Education in the Era of Collaborative Innovation}

As we know, the economy of the 21 st century is an economy under the condition of world economic integration, which guided by knowledge decision-making. The collaborative innovation, which will have a significant impact on all fields of human economic and social activities, as well as on the existing modes of production, life and thinking. It will also have a severe impact on adult education and pose severe challenges.

\subsection{The Development of Information Technology Has Changed the Traditional Adult Education Model}

However, the extensive application of modern information technology gives new meanings to "teaching" and "learning". The function of teachers changes from the traditional teaching information provider to the collaborator and guide in the process of students' knowledge seeking, while the students change from the original passive receiver to the active participant of learning and become the master of knowledge. In other words, the role of the teacher has transformed from the traditional image of "teacher's interpretation" of "preaching, teaching and clarification" into the role of the student's inspiration and promoter. In addition, the rapid development of network information technology has also changed the tra- 
ditional teaching methods, multimedia, slide instead of blackboard, chalk and other traditional teaching tools. The teacher can use the ready-made computer aided teaching software or the multimedia material library, choose the appropriate part to use in the explanation. You can also use PowerPoint or some multimedia production tools, write your own presentation, or use charts, animation, etc. to show the dynamic process of change and theoretical model.

At the same time, the establishment of Internet platform supported by information technology also creates good conditions for the implementation and development of adult education. The Internet connects research institutions, universities, libraries and other information resources all over the world. Teachers from all over the world can provide online teaching guidance to students through the Internet, such as MOOC, BBS forum, chat room, online live video teaching or online video recording and broadcasting. Students can also choose the right place according to their actual situation, choose and download the right learning materials from the Internet at their own convenience, and watch the online videos to study in their own way. We believe that the network of adult education has penetrated into the traditional teaching process, and gradually affected and changed the traditional education model, and at the same time to the present "quality education" promotion has played an inestimable role.

\subsection{The Promotion of "Quality-Oriented Education" Promotes the New Adult Education Mode with the Core of "Innovation"}

In retrospect, we will find that there have been two revolutions in the evolution of human learning. The first was in $300 \mathrm{BC}$, marked by the establishment of private schools by Confucius and the teaching by Socrates. The second was in the 16th century, marked by the establishment of the classroom learning system by Comenius, which introduced the industrial production method into education and established the one-to-many teaching method. As one of the four ancient civilizations of China, education has always been the most noble and dignified chapter in its glorious history. But until the founding of the People's Republic of China, we still followed the private school system of education thought of Confucius. After the founding of the People's Republic of China, it was only in the 1980s that a new educational idea gradually began to emerge, namely "strengthening the foundation, developing intelligence and cultivating non-intellectual factors", that is, emphasizing quality-oriented education. The promotion of quality-oriented education should cultivate students' active learning, independent thinking, practical ability and innovative spirit. Innovation consciousness, innovation ability is not born, although it has a certain connection with human talent, but fundamentally is the result of the nurture and education.

\section{Collaborative Innovation Brings Challenges to Adult Education}

\subsection{Small Scale, Lack of Characteristics of Adult Education}

With the advent of the era of knowledge economy, the amount of information 
people have tends to be infinite, the frequency of knowledge update is accelerating. New knowledge is constantly emerging, and the life of knowledge is shortening. In order to meet the challenge of knowledge explosion, people increasingly absorb new knowledge and learn new skills as an important means of their own survival and development. The emergence of this pattern will inevitably lead to the increasingly rich and diversified subjective and objective needs of the society for adult education, and therefore the scale, quality and characteristics of the existing adult education can adapt to meet the challenges. Due to historical reasons and the continuous expansion of enrollment in colleges or universities, China's adult education institutions are inadequate investment and slant small, lack of features, which are difficult to upgrade the scale and quality, in the face of the arrival of the era of knowledge economy, some even face the survival crisis again.

Under the influence and function of knowledge economy, in order to meet the needs of knowledge economy development, adult education should transfer the training goal and task focus, and promote the development of adult education to the depth and breadth. The main performance is as follows:

First, the focus of the task will shift to the training of knowledge, skills and intelligent talents as the main target of high-end training;

Second, the scope of adult education should extend to those who have received university or postgraduate education as the main object, and the education model based on updating, expanding and supplementing high-tech knowledge and modern management knowledge;

Third, the education of record of formal schooling based on the popularization of popular education, and the emphasis turn to the education form with two or three record of formal schooling as the main content;

Fourth, Implement diversified investment, expand the existing scale moderately, increase the protection of intellectual property rights, and protect human resource development and innovative research and development in the form of law. For example, adult education and training fund can be set up to ensure the funding source of human resource development and innovative research and development.

\subsection{The Unreasonable Professional and Curriculum Setting and the Outdated Teaching form of Adult Education}

The advent of the era of knowledge economy will inevitably cause fundamental changes in the curriculum system and teaching arrangements of adult education. Adult education of learning new theories, knowledge and skills, while focusing on improving humanistic quality, tapping potential and creativity. According to this standard, there is still a problem of focusing on knowledge education in adult education in China, and there is still a big gap in quality and innovation education. This requires adult education to pay attention to teach the educated high-tech knowledge and understand the nature of high-tech knowledge and the law of the way of thinking, for them to explore new things and cultivate the ability to innovate lay a foundation. In terms of specialty and curriculum setting, it is neces- 
sary to break the inter-disciplinary barriers, strengthen the inter-disciplinary logic and structural connection, and try our best to reflect the cross, penetration and integration of multi-disciplinary knowledge reflecting the characteristics of high-tech development into teaching.

In the face of high-tech knowledge and the trend and characteristics of social development, we can learn from the successful experience of adult education reform in developed countries and reasonably set up the teaching content and curriculum system in combination with its own actual situation. In addition, in the era of knowledge economy, people need to learn, master and be able to use the information with each passing day in the shortest time, the traditional "infusing", "cramming" teaching methods and the emphasis on systematic, complete, detailed and thorough methods, is no longer suitable for adult education teaching. Teachers, teaching materials and classroom teaching as the main content of the teaching form is challenge, and becoming more and more popular for people to learn the adult education school model, and the wide application of computer, multimedia and network will speed up the modernization of educational technology and means.

\section{Countermeasures for the Development of Adult Education under the Collaborative Innovation Environment}

\subsection{Changing Traditional Educational Concepts and Adhering to Market-Oriented and Industrialized Operations}

Nowadays, people accept adult education for improving their own cultural accomplishment and personal competitiveness in the society. Compared with the investment in education and the return after education, the individual gains the most. The concept of consumer education has become increasingly popular. Education is growing as a huge industry and consumers will have more choices. In the modern society, the adult education must according to the concept of the education industry, use the dual regulation mechanism of plan and market, and determine the talent cultivation program according to the market demand, carry out the industrialization operation, and push the school-running institution to the market.

Therefore, adult education takes the initiative to change the traditional education ideas, to meet the challenge of the consumer education. According to the market operation mechanism, realize the industrialization and the industrialization operation, and according to the laws of the market economy, develop the feasible and accord with the characteristics of its operating mechanism, improve the economic benefits of school running, promote the healthy development of their own.

\subsection{Make Full Use of Adult Education and Actively Promote the Combination of Production, Learning and Research}

In the era of collaborative innovation, the rapid development of science and technology has brought unprecedented huge changes to the economy and society, and adult education is a new form of education that ADAPTS (Analo- 
gue-Digital-Analogue Process and Test System) to collaborative innovation in modern society. in the tide of science and technology of the society, only by one-time education to acquire knowledge is far from enough, we must rely on the continuous adult education, learning new knowledge, in order to keep up with the trend of social development.

We know that if we want to turn education into scientific research results and economic benefits, we need to apply new technologies to knowledge innovation, and to establish effective mechanisms for the organic integration of knowledge in production, dissemination and application. The combination of production, learning and research is an important way for universities to carry out education and technological innovation. It mainly refers to the innovation cooperation between enterprises, universities and research institutes in the process of technological innovation, including cooperative research, cooperative development and technology transfer, under the situation of sharing risks, benefits, complementary advantages and common development. The implementation of adult education in institutions of higher learning calls for the strengthening of the integration of production, learning and research, and the vigorous promotion of cooperation between universities, research institutions and industry. enterprise technology innovation can also shift to graduate students of adult education colleges and universities and research institutions, make people in learning book knowledge at the same time, to the enterprise scientific research achievements, this is not only the spread of knowledge, the fastest the most effective way, it also highlights the strategic basic status of adult education. Cooperation between large enterprises and universities in adult education is a common way of industry-university-research cooperation.

\subsection{Using Modern Educational Technology to Optimize Network Teaching and Build a Network Platform for the Development of Adult Education}

At present, the modern educational technology represented by the computer multimedia network plays a very important role in promoting the modernization of education, MOOC (Massive Open Online Courses) education platforms such as Coursera. The most important thing is to perfect the network teaching system to build the development network platform of adult education. In the distance education teaching system, the network-teaching environment of online inspection and detection, cooperation and communication and two-way feedback should provide. In the organization and compilation of multimedia courseware, the students' active exploration and innovation spirit should be cultivated, and the courseware system centered on "learning" should establish.

In the teaching system, there should be a collaborative communication link for students and teachers to discuss and answer questions, and conduct timely and effective two-way feedback, discuss and exchange results, and propose shortcomings for improvement. Actively strive to build a dynamic network platform, according to the characteristics of students in accordance with the characteristics 
of teaching, stimulate students' enthusiasm for learning. At the same time, adult education institutions should also increase the network publicity efforts, strive to play a good school website this live advertising, through the network platform to promote their own, attract students, and optimize the network teaching, in order to achieve a win-win situation.

\subsection{Establish Brand Awareness, Add Training Points for Specialized Degrees with Special Features, and Build an Open All-Dimensional Development Model}

The quality of education is an important factor in the healthy development of education. Similarly, for adult education, only high quality adult education can guarantee the development of adult education. Therefore, adult education should always take quality as its lifeline; constantly introduce new technology, new ideas, reform education teaching methods, improve the quality of education. At the same time, it is necessary to establish brand awareness, build a brand specialty suitable for its own characteristics, pay attention to the cultural value and economic value of the brand specialty, develop brand characteristics, and walk out a development path with brand specialty characteristics. At the same time, according to the characteristics of brand major to add some special professional degree training points, make the special major bigger and stronger, firmly grasp the "special major" this central link, improve the quality of education and teaching, constantly tap their potential, optimize the allocation of resources, and promote their sustainable development. In strengthening the construction of brand of professional at the same time, also should strengthen the management of teacher's team construction, the daily teaching management, perfect the teaching management system. For the comprehensive improvement of teaching quality and create brand professional to create a good foundation and the safeguard, the formation of teacher management, teaching quality, professional brand cooperation pattern, construct open all-round development mode.

\section{Acknowledgements}

This work was supported by the Anhui provincial higher education teaching research project (Joint cultivation mechanism of adult education under collaborative innovation environment, Project No. 2018jyxm0603).

\section{Conflicts of Interest}

The author declares no conflicts of interest regarding the publication of this paper.

\section{References}

Bitton, A., Ellner, A., Pabo, E., Stout, S., Sugarman, J. R., Sevin, C., Goodell, K., Bassett, J. S., \& Phillips, R. S. (2014). The Harvard Medical School Academic Innovations Collaborative: Transforming Primary Care Practice and Education. Academic Medicine, 89, 1239-1244. https://doi.org/10.1097/ACM.0000000000000410 
Bodycott, P. (2009). Choosing a Higher Education Study Abroad Destination: What Mainland Chinese Parents and Students Rate as Important. Journal of Research in International Education, 8, 349-373. https://doi.org/10.1177/1475240909345818

Dwyer, J. A. (2013). Innovation in Undergraduate/Postgraduate Clinical Experience in Collaborative Project with Tertiary Sector, Industry and Education Training and Workforce Development. International Journal of Mental Health Nursing, 22, 7-8.

Glicken, A. D., Deutchman, M., Dolce, M. C., Evans, C., Smith, L., \& Fuccillo, R. (2013). Working Across Health Professions to Promote Oral Health in Primary Care: Collaborative Innovations in Education and Practice. Journal of Interprofessional Care, 27, 192-192.

Guan, D. (2018). Collaborative Innovation of Ideological and Political Education in Colleges and Universities Based on Philosophical Cognitive Thinking. Educational Sciences-Theory \& Practice, $18,1722-1729$.

Ssempebwa, J., Eduan, W., \& Mulumba, F. N. (2012). Effectiveness of University Bridging Programs in Preparing Students for University Education: A Case from East Africa. Journal of Studies in International Education, 16, 140-156.

https://doi.org/10.1177/1028315311405062 